It is conceivable that the onset of pneumomediastinum occurred during the episode of asthma on the night before presentation; however, the mild nature of this attack suggests otherwise. This attack was probably a factor in increasing the amount of mediastinal air following the initial leak initiated by the patients unusual exertion.

This case represents the first report of pneumomediastinum occurring as a result of surf lifesaving. Of importance is the associated history of mild chronic asthma and this case also represents the first description of this complication of asthma in an asthmatic athlete. The importance of impeccable control of asthma in the athlete-and in particular the monitoring of lung function before activities involving straining and the Valsalva manoeuvre-and the correct use of prophylactic medication is highlighted.

1 Munsell WP. Pneumomediastinum: a report of 20 cases and review of the literature. $\mathcal{F} A M A$ 1967;202:689-93.

2 Miller E, Spiekerman RE, Hepper NG. Pneumomediastinum resulting from performing Valsalva manoeuvers num resulting from performing Valsalva mant
3 Abolnik I, Lossos IS, Breuer R. Spontaneous pneumomediastinum: a report of 25 cases. Chest 1991;100: 93-5.

4 Casamassima AC, Sternberg T, Weiss F. Spontaneous pneumopericardium: a link with weight lifting? Phys Sports

5 Morgan EJ, Henderson DA. Pneumomediastinum as a complication of athletic competition. Thorax 1981;36:155-

6 Vesk A, Houston CS. Mediastinal emphysema in mountain climbers. Heart Lungs 1977;6:799-800.

7 Doyle M, Given F. Pneumomediastinum as a complication of athletic activity. Ir $\mathcal{F} M e d S c i$ 1987;156:272-3.

8 Haynes RJ, Evans RJ. Pneumomediastinum after rugby training. Brf Sports Med 1993;27:37-8.

9 Cements MR, Hamilton DV. Pneumomediastinum as a complication of fast bowling in cricket. Postgrad Med $\mathfrak{f}$ 1982;58:435.

10 Edmonds C, Lowry C, Pennefather J. Diving and subaquatic medicine. Oxford: Butterworth Heinemann, 1992:97-9.

11 Raymond LW. Pulmonary barotrauma and related events in divers. Chest 1995;107:1648-52.

12 Harker CP, Neuman TS, Olson LK, Jacoby I, Santos A. The roentgenographic findings associated with air embolism in sport scuba divers. F Emerg Med 1993;11:443-9.

13 Komatsu H, Enzan K, Mitsuhata H, Hasegawa J, Matsumoto $S$, Suzuki $M$, et al. A case of pneumomediastinum caused by closed tracheal injury during the game of Kendo

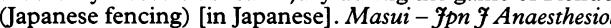
1992;41:673-6.

14 Panacek EA, Singer AJ, Sherman BW, Prescott A, Rutherford WF. Spontaneous pneumomediastinum: clinical and natural history. Ann Emerg Med 1992;21:1222-7.

15 Bratton SL, O'Rourke PP. Spontaneous pneumomediastinum. F Emerg Med 1993;11:525-9.

\title{
Exercise induced leg pain-chronic compartment syndrome. Is the increase in intra-compartment pressure exercise specific?
}

\author{
Nat Padhiar, John B King
}

\begin{abstract}
Intra-compartment pressure studies remain the main investigative method in diagnosing chronic compartment syndrome (CCS). Standard exercise protocols have been used to cause the raise in pressure measured in the laboratories. This case suggests that CCS cannot be excluded without the specific sports activity being used to raise the intracompartmental pressure.
\end{abstract}

(Br $\mathcal{F}$ Sports Med 1996;30:360-362)

Key terms: chronic compartment syndrome; intracompartmental pressure; exercise

Exercise induced leg pain is a common

Department of Sports Medicine, The London Hospital Medical College, London E1 4DG, United Kingdom N Padhiar, honorary consultant podiatrist J B King, consultant orthopaedic surgeon

Correspondence to: Mr N Padhiar.

Accepted for publication 20 February 1996

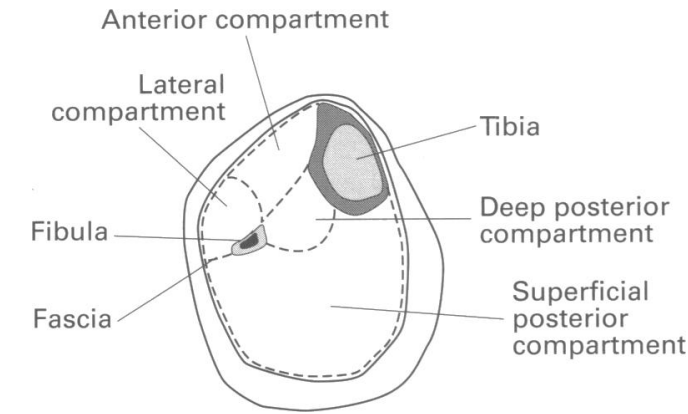

Figure 1 Transverse section through the left leg showing the four compartments. problem encountered by young athletes after an increase in activity or at the start of the season. ${ }^{1}$ The terms shin splints ${ }^{2}$ or freshers leg $^{3}$ are often used to describe the condition. These terms are non-specific and are falling out of favour. The pivotal symptom is pain, which occurs on exercise and is relieved by a variable period of rest. The cause of pain will usually fall into one of the following four categories:

(1) Pain of bony origin, for example focal stress fracture or diffuse micro-stress fractures. ${ }^{4-6}$

(2) Pain of osteofascial origin, for example periostitis and medial tibial stress syndrome. $^{78}$

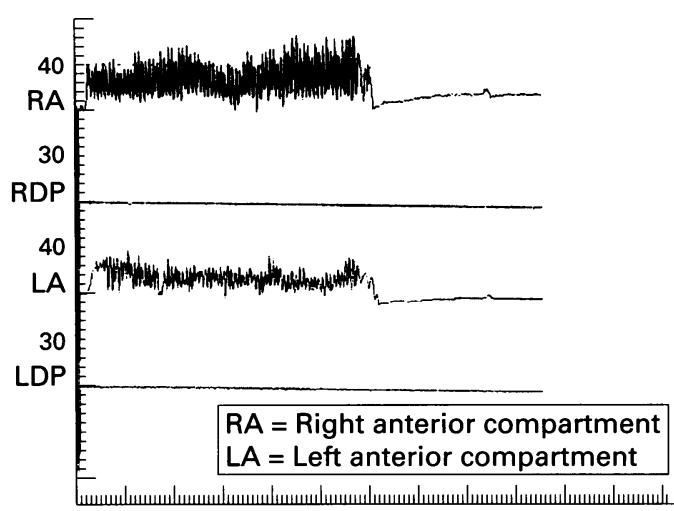

Figure 2 Pressure change following jogging on the spot. 


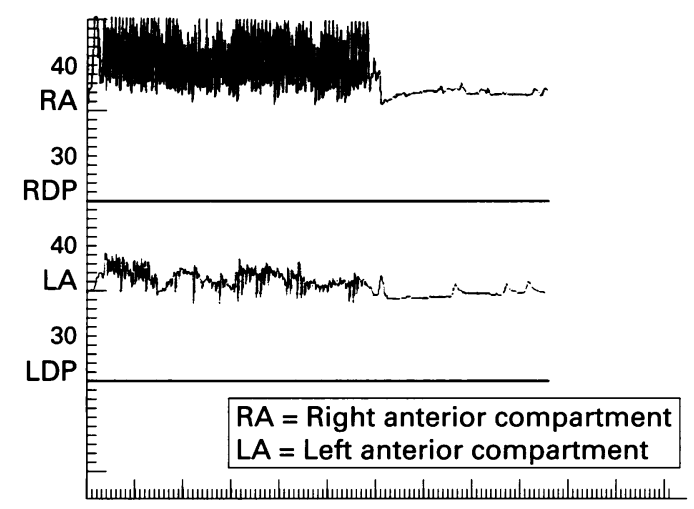

Figure 3 Pressure change following step aerobic routine.

(3) Pain of muscular origin, for example chronic compartment syndrome..$^{9-11}$

(4) Pain of nerve compression, for example superficial peroneal nerve compression. ${ }^{12}$

Chronic compartment syndrome is the most common cause, particularly affecting the anterior and deep posterior compartments of the leg (fig 1). The condition is characterised by an increase in intra-compartmental pressure, resulting in pain ${ }^{13}$ which may well be localised.

\section{Case report}

A 32 year old Caucasian woman presented with activity related pain affecting the anterior compartment of the right leg. She was a step aerobic instructor with average of six high impact classes a week. Resting and dynamic pressure studies were performed using a slit catheter ${ }^{14}$ and a Medex pressure transducer as described by Barnes et al. ${ }^{15}$

A "standard" exercise protocol (jogging on the spot for 60 seconds with 30 seconds rest) was used and the pressure remained within normal limits $(<40 \mathrm{~mm} \mathrm{Hg})^{15}$ (fig 2$)$. A study using a step aerobic routine showed a dramatic rise in the pressure $(>40 \mathrm{~mm} \mathrm{Hg}),{ }^{15}$ the normal diagnosis of CCS (fig 3).

After failed conservative management she underwent superficial fasciotomy of the anterior compartment (fig 4). She returned to her sport 12 weeks after the operation.

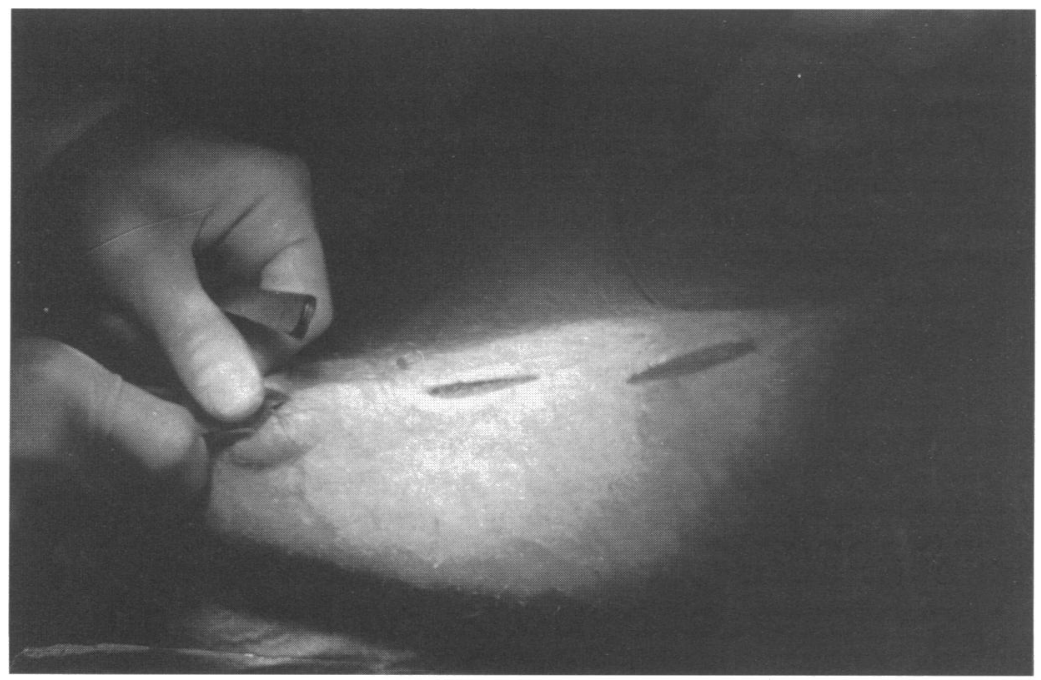

Figure 4 Superficial fasciotomy

\section{Discussion}

Chronic compartment syndrome of the leg was first described by Mavor in $1956^{\circ}$ and is characterised by exercise induced pain, swelling, and impaired muscle function. ${ }^{13}$ Increase in intra-compartmental pressure on exercise is regarded as diagnostic but there is a variation in parameters used by various authors. French and Price ${ }^{10}$ and Wallenstein ${ }^{16}$ considered raised intra-compartmental pressure at rest after exercise to be crucial; Puranon and Alavaikko ${ }^{11}$ cite raised intra-compartmental pressure during exercise; McDermot et al ${ }^{17}$ claim muscle contraction pressure to be critical; and Styf et al ${ }^{18}$ regarded increase in muscle relaxation pressure to be the important variable.

Exercise protocol has also varied with individual researchers. Styf et al ${ }^{18}$ used the foot and shoe attached to a device loaded with $4-6 \mathrm{~kg}$ and linked it to an ergometer. Patients were asked to dorsiflex both feet once a second for five minutes. Logan et al ${ }^{19}$ and Rorabeck et al ${ }^{20}$ used a treadmill with varying speeds to exercise their subjects. Allen and Barnes ${ }^{1}$ used jogging on the spot for 60 seconds with 30 seconds rest, which was repeated three times and results averaged.

\section{CONCLUSION}

Despite variations in detail, an exercise protocol is generally used in an attempt to demonstrate pressure changes in the compartment affected by CCS. Our case suggests that changes in pressure may only come about when a specific activity is used, and adherence to a set protocol may not reveal some cases.

Our grateful thanks to Amineh Khatib and Tahir Mahmud, medical physicists, for their dedication and expertise in setting up the ICP monitoring system. Our sincerting up the ICP monitoring system. Our sincere thanks to the following for supporting this study: Medex Ltd, Ellman (UK) Ltd, Baurfeind (UK) Ltd, Canonbury Products Ltd, and
Special thanks to Mr S Keswick.

1 Allen MJ, Barnes MR. Exercise pain in the lower leg. $f$ Bone foint Surg Br 1986;68B:818-23.

2 Soint Surg Br. The shin splints syndrome. Medical aspects and differential diagnosis. Am $\mathcal{f}$ Surg 1967;114:875-81.

3 Subotnik SI. The shin splints syndrome of the lower extremity. F Am Podiatr Assoc 1976;66:43-5.

4 Devas MB. Stress fractures. Edinburgh: Churchill Livingstone, 1975 .

5 Puranon J. The medial tibial syndrome, exercise ischaemia in the medial fascial compartment of the leg. $\mathcal{F}$ Bone foint Surg $\mathrm{Br}$ 1974;56B:712-5.

6 Jackson DW. Shin splints-an update. Physician Sports Med 1980;10:55-61.

7 Devas MB. Stress fracture of the tibia in athletes or "Shin soreness". F Bone foint Surg Br 1958;40B:227-39.

8 Mubarak SJ, Gould RN, Lee YF, Schmidt DA, Hargens AR. The medial tibial stress syndrome. Am f Sports Med 1982; 10:201-5.

9 Mavor GE. The anterior tibial syndrome. $f$ Bone foint Surg Br 1956;38B:513-7.

10 French EB, Price WH. Anterior tibial pain. BMF 1962;ii: 1290-6.

11 Puranon J, Alvaikko A. Intracompartment pressure increase on exertion in patients with chronic compartment syndrome in the leg. $\mathcal{F}$ Bone foint Surg Am 1981;63A:1304-9.

12 Lorei MP, Hershman EB. Peripheral nerve injuries in athletes treatment and prevention. Sports Med 1993;16: $130-47$.

13 Reneman RS. The anterior and lateral compartmental syndrome of the leg due to intensive use of muscles. Clin Orthop 1975;113:69-80.

14 Rorabeck CH, Castle GSP, Logan J, Hardy R. The slit catheter: a new device for measuring intracompartmental pressure. Surg Forum 1980;31:513-5.

15 Barnes MR, Gibson MJ, Scott J, Bentley S, Allen MJ. A technique for the long term measurement of intracompart-
ment pressure in the lower leg. $\mathcal{F}$ Biomed Eng 1985;7:35-9.

16 Wallenstein R. Results of fasciotomy in patients with medial tibial syndrome or chronic anterior compartment syndrome. F Bone foint Surg Am 1983;65A:1252-5. 
17 McDermot AG, Marble AE, Yabsley RH, Phillips MB. Monitoring dynamic anterior compartment pressures during exercise:a new technique using the STIC catheter. $\mathrm{Am}$ I Sports Med 1982;10:83-9.

18 Styf J, Korner L, Suurkula M. Intramuscular pressure and (n) muscle blood flow during exercise in chronic compartmen
19 Logan JG, Rorabeck CE, Castle GSP. The measurement of dynamic compartment pressure during exercise. $\mathrm{Am} \mathcal{f}$ Sports Med 1983;4:220-3.

20 Rorabeck CH, Bourne RB, Fowler PJ, Finlay JB, Nott L. The role of tissue pressure measurement in diagnosing chronic anterior compartment syndrome. Am $₹$ Sports Med chronic anterior

\title{
Late deterioration after decompression illness affecting the spinal cord
}

\author{
J Dyer, P Millac
}

\begin{abstract}
A former amateur diver presented with a progressive paraparesis. Thirteen years previously he had developed acute spinal cord dysfunction immediately after dry hyperbaric exposure. He had completely recovered motor function in the intervening period. No alternative reason for the later decline emerged from detailed investigation.

(Br F Sports Med 1996;30:362-363)
\end{abstract}

Key terms: decompression illness; late paraparesis

Dysbarism (decompression illness) is one of the most common identifiable causes of nontraumatic ischaemic myelopathy. ${ }^{1}$ Histological examination of the spinal cord of divers who have suffered dysbarism can reveal widespread damage, with hyalinised blood vessels and demyelination, even in those who have subsequently recovered. There may also be degeneration of nerve fibres in the dorsal and lateral spinal columns, with gliosis and white matter atrophy. ${ }^{2-6}$

\section{Case report}

A 37 year old Caucasian man presented with weakness and spasticity of his legs, worsening since the onset six months earlier.

Thirteen years previously he had suffered a spinal cord decompression illness. At no other time had he had any significant disease or diving accident. The decompression illness was experienced following a closely monitored hyperbaric exposure to a maximum of 6.5 atmospheres. He shared the compression chamber with four other divers, none of whom was adversely affected. The chamber pressure was controlled from outside following the standard national guidelines then available (1978).

Thirty minutes after recompression he experienced paraesthesia in his right buttock. After one hour he had developed weakness of both legs (MRC grade 3/5). He managed to return to the chamber for therapeutic recompression within $2 \frac{1}{2}$ hours, which was at 6 atmospheres for $5 \frac{1}{2}$ hours. During this period his decompression illness deteriorated, most notably in that he developed urinary retention, which required catheterisation. He also had reduced pin prick, light touch, and temperature sensation below his umbilicus, with pain around his lumber spine. Vibration and proprioception sense were unaffected; his legs remained as weak though he now showed hyperreflexia. After transportation to a Royal Navy base he had further recompression. The following day he had a third recompression but on this occasion breathing oxygen enriched air. Over these two days there was a steady recovery to normality, with the exception of a slight deficit in light touch and proprioception below his umbilicus and a bandlike sensation around his waist. Negative investigation in the weeks following this were: CSF and urine microscopy, blood urea and electrolytes, glucose, full blood count, VDRL, chest $x$ ray, electromyelography, visual evoked responses, and whole spine myelography.

Without further dives he presented 13 years later with spastic paraparesis developing over six months. His minor sensory impairment was unchanged. Bladder, bowel, and sexual function are unaffected. He has never taken regular medication, drank alcohol moderately, has no relevant family history, but had recently become so incapacitated that he was unable to continue as a building contractor. All leg muscles have MRC grade 4/5 power with increased tone, global hyperreflexia, and extensor planter reflexes. The previous investigations remained normal, as did his HTLV 1, CSF electrophoresis for IgG, and magnetic resonance imaging (MRI; T2 weighted spin echo) of his brain.

MRI of his cervical and thoracic spine (T1 weighted spin echo), scanned in sagittal and axial section, showed focal narrowing of the cord between $\mathrm{T} 2$ and $\mathrm{T} 7$, with expansion at either end to normal calibre. In the narrow section there is increased epidural fat, indicating that this is a long standing lesion (figure).

Over the four years following this latter deterioration, his neurological condition worsened only subjectively. Presently he requires walking sticks but otherwise reports no new changes. 